\title{
NONINVASIVE MECHANICAL VENTILATION IN THE TREATMENT OF ACUTE CARDIOGENIC PULMONARY EDEMA
}

\author{
Marcelo Park and Geraldo Lorenzi-Filho
}

Park M, Lorenzi-Filho G. Noninvasive mechanical ventilation in the treatment of acute cardiogenic pulmonary edema. Clinics. 2006;61(3):247-52.

Current literature was searched by using the MEDLINE database to find consistent evidence regarding the use of noninvasive mechanical ventilation in patients with acute cardiogenic pulmonary edema. 18 studies demonstrating that noninvasive ventilation applied by continuous positive airway pressure (CPAP) or bilevel positive airway pressure (bilevel-PAP) is safe, and that the two approaches have similar effects and are effective in preventing endotracheal intubation in patients with respiratory distress of cardiac origin, were found. The results support the concept that positive intrathoracic positive pressure must be seen as a nonpharmacological form of treatment of acute pulmonary edema rather than only a supportive measure.

KEYWORDS: Pulmonary edema. Respiratory failure. Artificial respiration. Mechanical ventilator. Respiratory therapy.

\section{INTRODUCTION}

Acute cardiogenic pulmonary edema is a common cause of acute respiratory distress among patients presenting to the emergency departments and intensive care units. Hypoxemia, sometimes associated with hypercapnia, is a common feature in the clinical presentation of acute cardiogenic pulmonary edema. Standard medical therapy includes diuretics, vasodilators, and inotropics, and it results in rapid improvement of the respiratory symptoms. In this context, oxygen delivered through a face mask is the basic respiratory support. Although many patients respond rapidly to standard treatment, a significant number progress to severe respiratory distress leading to endotracheal intubation with its associated complications. ${ }^{1-9}$

Positive pressure applied in the airway can relieve the respiratory failure and also improve the cardiovascular

Intensive Care Unit, Emergency Department, Hospital das Clínicas, São Paulo University Medical School - São Paulo/SP, Brazil.

Sleep Laboratory, Respiratory Division, Heart Institute, São Paulo University Medical School - São Paulo/SP, Brazil.

E-mail: mpark@uol.com.br

Received for publication on January $08,2006$.

Accepted for publication on March 17, 2006. function, especially in severe cardiac-dysfunction patients. ${ }^{10,11}$ These multiple actions of positive pressure can act synergically in the treatment of patients with respiratory distress and impaired cardiac function. ${ }^{1-9,12}$ Noninvasive use of positive pressure delivered through a face mask reduces the need for endotracheal intubation in patients with acute cardiogenic pulmonary edema. ${ }^{1-9}$

There are 2 modes for applying noninvasive positive pressure: continuous positive airway pressure (CPAP) (ie, constant pressure during the whole respiratory cycle) and bilevel positive airway pressure (bilevel-PAP) (ie, adding to a continuous expiratory pressure an inspiratory support pressure above the expiratory pressure to reduce the inspirational respiratory work). In this report, we review the main physiological characteristics of CPAP and bilevel-PAP on respiratory and cardiovascular function as well as the evidences to their use in the clinical setting.

\section{CARDIOVASCULAR AND RESPIRATORY PHYSIOLOGY}

Cardiovascular effects of positive pressure ventilation are primarily modulated by the effects on preload and 
afterload. Venous return can be reduced when positive pressure ventilation is applied in hypovolemic patients, resulting in reduced cardiac output. In normovolemic patients, the pulmonary insufflation raises the abdominal pressure, and thus it raises the mean circulatory pressure, keeping the venous flow stable. ${ }^{13}$ Pleural pressure augmentation raises the pericardial pressure and reduces the myocardial transmural pressure as well as the ventricle diameter, ${ }^{14}$ resulting in low ventricle surface tension and afterload, mainly in patients with a dilated ventricle. ${ }^{10,11,15}$ This anatomo-physiological alteration is associated with a reduction in regurgitant flow through the mitral valve. ${ }^{11}$

Airway positive pressure has well-known effects on respiratory function in patients with cardiogenic pulmonary edema. The improvement in pulmonary compliance and shunt are associated with alveolar recruitment. ${ }^{10,15}$ Reduction of inspiratory load is associated with the improvement of pulmonary compliance and the inspiratory pressure support when bilevel-PAP is applied. ${ }^{10,15}$ A CPAP of $10 \mathrm{~cm} \mathrm{H}_{2} \mathrm{O}$ reduces the pleural pressure swing and improves tidal volume and $\mathrm{PaO}_{2} / \mathrm{FiO}_{2}$ ratio during the spontaneous ventilation in patients with heart failure; these effects are more striking when using bilevel-PAP ventilation with an expiratory pressure (EPAP) of $10 \mathrm{~cm} \mathrm{H}_{2} \mathrm{O}$ and inspiratory pressure (IPAP) of $15 \mathrm{~cm} \mathrm{H}_{2} \mathrm{O} .^{10,15}$

\section{CLINICAL USE OF NONINVASIVE POSITIVE PRESSURE VENTILATION IN ACUTE CARDIOGENIC PULMONARY EDEMA}

\section{Continuous possitive airway pressure (CPAP)}

Two randomized studies have shown an improvement in hypoxemia, hypercapnia, and endotracheal intubation rate in patients with acute cardiogenic pulmonary edema using CPAP as compared to treatment with standard respiratory support (ie, oxygen delivered by mask). ${ }^{1,2,9}$ These results have been reproduced in small physiological trials ${ }^{5-}$ ${ }^{7,9,16}$ as well as in other clinical trials. ${ }^{5,69}$ The impact of CPAP on mortality in patients with acute cardiogenic pulmonary, was reduced in some trials ${ }^{5,7,9}$ but not in others. ${ }^{1,2}$

The different results obtained may be related to methodology, including patient selection and levels of CPAP. One interesting point is that in the first randomized trial, ${ }^{1}$ the patients enrolled were severely hypercapnic. In addition, the improvement in $\mathrm{PaCO}_{2}$ after 30 minutes was significantly greater in the CPAP group ( $58 \pm 8$ to $46 \pm 4 \mathrm{~mm}$ $\mathrm{Hg}$ ) than in the oxygen group ( $64 \pm 17$ to $62 \pm 14 \mathrm{~mm} \mathrm{Hg})$.

The levels of CPAP used in the trials varied, but most of them used $10 \mathrm{~cm} \mathrm{H}_{2} \mathrm{O}{ }^{1,5,7}$ Alternatively, in one trial, the level of CPAP was titrated from $2.5 \mathrm{~cm} \mathrm{H}_{2} \mathrm{O}$ to $12.5 \mathrm{~cm}$
$\mathrm{H}_{2} \mathrm{O}$ over 2.5 hours. $^{2}$ Park et $\mathrm{al}^{6}$ showed that $5 \mathrm{~cm} \mathrm{H}_{2} \mathrm{O}$ of CPAP was not superior to conventional therapy in terms of tracheal intubation. Taken together, the target CPAP pressure for patients with acute pulmonary edema should be $10 \mathrm{~cm} \mathrm{H}_{2} \mathrm{O}$ for most patients.

\section{Bilevel positive airway pressure (bilevel-PAP)}

The effectiveness of the use of bilevel-PAP in the treatment of acute cardiogenic pulmonary edema has been tested in 6 clinical trials, with different results. ${ }^{3-8}$ These differences may be related to different methodologies. Comparing bilevel-PAP with oxygen, Masip et al, ${ }^{4}$ Nava et al, ${ }^{8}$ Park et al, ${ }^{5,6}$ and $\mathrm{Crane} \mathrm{et}^{\mathrm{al}}{ }^{7}$ have shown physiological improvement and reduction in endotracheal intubation rates. On the other hand, comparing bilevel-PAP and CPAP, Park et $\mathrm{al}^{5}$ and Crane et $\mathrm{al}^{7}$ did not find physiological or clinical improvement. Mehta et $\mathrm{al}^{3}$ found physiological improvement but with a rise in myocardial infarction rate. In a pilot study comparing bilevel-PAP and CPAP, Park et $\mathrm{al}^{6}$ found that $5 \mathrm{~cm} \mathrm{H}_{2} \mathrm{O}$ of CPAP was not associated with avoidance of endotracheal intubations, but bilevel-PAP with an expiratory pressure (EPAP) of $3 \mathrm{~cm} \mathrm{H}_{2} \mathrm{O}$ and inspiratory pressure (IPAP) of $8 \mathrm{~cm} \mathrm{H}_{2} \mathrm{O}$ was.

The various levels of airway pressure used in those trials might explain some result differences among them. Nava et $a l,{ }^{8}$ in a multicenter European trial, enrolled 130 patients, 65 to oxygen support treatment and 65 to bilevelPAP with a mean EPAP of $6.1 \pm 3.2 \mathrm{~cm} \mathrm{H}_{2} \mathrm{O}$ and a mean IPAP of $14.5 \pm 21.1 \mathrm{~cm} \mathrm{H}_{2} \mathrm{O}$ over $11.4 \pm 3.6$ hours. In this trial, normocapnic $\left(\mathrm{PaCO}_{2} \mathrm{~d} \bullet 45 \mathrm{~mm} \mathrm{Hg}\right)$ patients using bilevel-PAP showed no improvement in endotracheal intubation and mortality rates, whereas, hypercapnic $\left(\mathrm{PaCO}_{2}\right.$ $>45 \mathrm{~mm} \mathrm{Hg}$ ) patients had a reduction in endotracheal intubation rates (oxygen, 29\% vs bilevel-PAP, $6 \% . P=$ 0.015). This finding was similar to that of Masip et al, ${ }^{4}$ where hypercapnic patients had a substantial physiological and probably clinical improvement when compared to normocapnic patients using similar airway pressures to those used by Nava et al. ${ }^{8}$ The incidence of hypercapnic patients was $49 \%$ in the study by Nava et $\mathrm{al}^{8}$ study, and it was $50 \%$ in the study by Masip et al. ${ }^{4}$ In contrast, Park et al ${ }^{5}$ found that even normo- or hypocapnic patients can experience beneficial effects in physiological and clinical terms from bilevel-PAP ventilation in an acute cardiogenic pulmonary edema setting, when compared to oxygen-alone treated patients. In the last study, 80 patients were enrolled, 26 to receive oxygen only, 27 to receive CPAP $(10 \mathrm{~cm}$ $\mathrm{H}_{2} \mathrm{O}$ ), and 27 to receive bilevel-PAP (EPAP $=10 \mathrm{~cm} \mathrm{H}_{2} \mathrm{O}$ and IPAP $=15 \mathrm{~cm} \mathrm{H}_{2} \mathrm{O}$ ); $19 \%$ of these patients were hypercapnic. The endotracheal intubation rate was $42 \%$ in the 
oxygen-alone group and 7\% in bilevel-PAP group. There are some differences in the populations enrolled to the studies of Nava et $\mathrm{al}^{8}$ and Park et al, ${ }^{5}$ but the most striking difference was the EPAP level used $\left(5 \mathrm{~cm} \mathrm{H}_{2} \mathrm{O}\right.$ vs $\left.10 \mathrm{~cm} \mathrm{H}_{2} \mathrm{O}\right)$. The real importance of the effect of EPAP on the respiratory and cardiovascular function is not yet clear in this setting, but it should be considered that $10 \mathrm{~cm} \mathrm{H}_{2} \mathrm{O}$ of EPAP can be safe and maybe more useful for supporting and treating acute cardiogenic pulmonary edema patients. ${ }^{5} \mathrm{An}$ inspiratory support pressure of $5 \mathrm{~cm} \mathrm{H}_{2} \mathrm{O}$ seems to be sufficient to relieve the respiratory distress and improve hemodynamic and respiratory variables. ${ }^{5,10,15}$

In a study comparing bilevel-PAP and high-dose nitrate therapy, Sharon et $\mathrm{a}^{17}$ found an increased myocardial infarction rate in the bilevel-PAP group. However, this study did not have an adequate control group, the rate of myocardial infarction was much higher than the other cited studies, ${ }^{4-8,16,18,19}$ and the diagnostic criteria of myocardial infarction was poor.

There is no conclusion about the mortality rate in acute cardiogenic pulmonary edema patients treated with bilevelPAP when compared to conventional treatment. In fact, only 1 study, performed by Park et al, ${ }^{5}$ has shown a reduction of mortality associated with bilevel-PAP at the 15-day follow-up. Other studies, such as those of Masip et al, ${ }^{4} \mathrm{Nava}$ et $\mathrm{al}^{8}{ }^{8}$ and $\mathrm{Crane}$ et $\mathrm{al}^{7}$ did not find a reduction in mortality rates, although there were different strategies in the respiratory support of patients.

\section{CPAP VS BILEVEL-PAP}

The use of CPAP or bilevel-PAP as a choice to treat and support acute pulmonary edema patients has recently been explored and reported. Mehta et $\mathrm{al}^{3}$ studied 27 patients, with 13 enrolled to receive $\mathrm{CPAP}$ at $10 \mathrm{~cm} \mathrm{H}_{2} \mathrm{O}$, and 14 enrolled to receive nasal bilevel-PAP with an EPAP of $5 \mathrm{~cm} \mathrm{H}_{2} \mathrm{O}$ and an IPAP of $15 \mathrm{~cm} \mathrm{H}_{2} \mathrm{O}$; they found an improvement in 30 minutes in the bilevel-PAP-treated group that was more accentuated in physiological outcomes such as heart rate, respiratory rate, $\mathrm{PaO}_{2}$, and $\mathrm{PaCO}_{2}$. In clinical terms, there was an improvement in the dyspnea score, but the study had to be prematurely stopped due to a high incidence of myocardial infarctions in the bilevel-PAP group. The causes of this unexpected event were not clarified. The authors suggested that the excessive intrathoracic pressure associated with bilevel-PAP was responsible for the adverse cardiovascular effects. However, when taking into account that the patients had presented with chest pain in the emergency room, it seems that in the $71 \%$ patients who were randomized to be treated with bilevel-PAP and presented CK-MB elevations, the myocardial infarction may have actually been the cause of the pulmonary edema and not the result of bilevel-PAP ventilation. More recently Park et al,${ }^{5,6}$ Cross et al, ${ }^{18}$ and $\mathrm{Crane}$ et $\mathrm{al}^{7}$ have found that CPAP was similar to bilevel-PAP in physiological and clinical outcomes, including a similar incidence of acute myocardial infarction rate. However, in the last study, CPAP was associated with an improvement in in-hospital survival. ${ }^{7}$

Facing hypercapnic acute cardiogenic pulmonary edema patients, the rationale to use bilevel-PAP is strong. ${ }^{3,1015}$ However, in contrast to the studies of Masip et $\mathrm{al}^{4}$ and Nava et $a l,{ }^{8}$ where the hypercapnic patients seemed to be better supported by bilevel-PAP, the study performed by Bersten et al, ${ }^{1}$ a CPAP of $10 \mathrm{~cm} \mathrm{H}_{2} \mathrm{O}$ was also effective in reducing the need for endotracheal intubation. Accordingly, Bellone et al, ${ }^{19}$ in a randomized, prospective study, found with high statistical power $(0.8)$ that 18 hypercapnic acute cardiogenic pulmonary edema patients ventilated with a CPAP of $10 \mathrm{~cm} \mathrm{H}_{2} \mathrm{O}$ had a similar endotracheal intubation requirement to that of 36 patients ventilated with bilevelPAP with an EPAP $=5 \mathrm{~cm} \mathrm{H}_{2} \mathrm{O}$ and pressure support sufficient to achieve $400 \mathrm{~mL}$ of tidal volume (CPAP $=5.5 \%$ vs bilevel-PAP $=11.1 \%, P=0.5$ ). The odds ratio graph of endotracheal intubation requirements of all studies comparing CPAP and bilevel-PAP are shown in Figure 1.

The issue of acute myocardial infarction was better studied in the trial of Bellone et al,${ }^{16}$ where with a statistical power of 0.8 , the incidence of acute myocardial infarct was similar in both groups studied: $13.6 \%$ of 22 patients treated with CPAP of $10 \mathrm{~cm} \mathrm{H}_{2} \mathrm{O}$ and $8.4 \%$ of 24 patients treated with bilevel-PAP with an EPAP of $5 \mathrm{~cm} \mathrm{H}_{2} \mathrm{O}$ and IPAP of $15 \mathrm{~cm} \mathrm{H}_{2} \mathrm{O}(P=0.46)$. The odds ratio graph of acute myocardial infarction after admission of all studies comparing CPAP and bilevel-PAP is shown in Figure 2.

\section{SEVERITY AND TIMING FOR APPLICATION OF NONINVASIVE VENTILATION}

Pulmonary edema has a wide spectrum of severity, and few patients have severe respiratory distress at entry into a study. In the study of Parket al, ${ }^{5}$ as in others, ${ }^{4}$ only $20 \%$ of the patients evaluated were enrolled with severe pulmonary edema. Therefore, it is likely that the effects of noninvasive ventilation are not uniform across the whole spectrum of cardiogenic pulmonary edema. ${ }^{20}$ In studies such as those of Nava et al, ${ }^{8}$ Park et al, ${ }^{5,6}$ Masip et al,${ }^{4}$ and Crane et al, ${ }^{7}$ the presence of a control group treated with oxygen allowed us to estimate the expected outcome for the particular population selected.

A delay in applying noninvasive ventilation is a possible explanation for hypercapnia in some patients. ${ }^{4}$ In contrast, when applying positive airway pressure early, low lev- 


\section{CPAP}

BIPAP

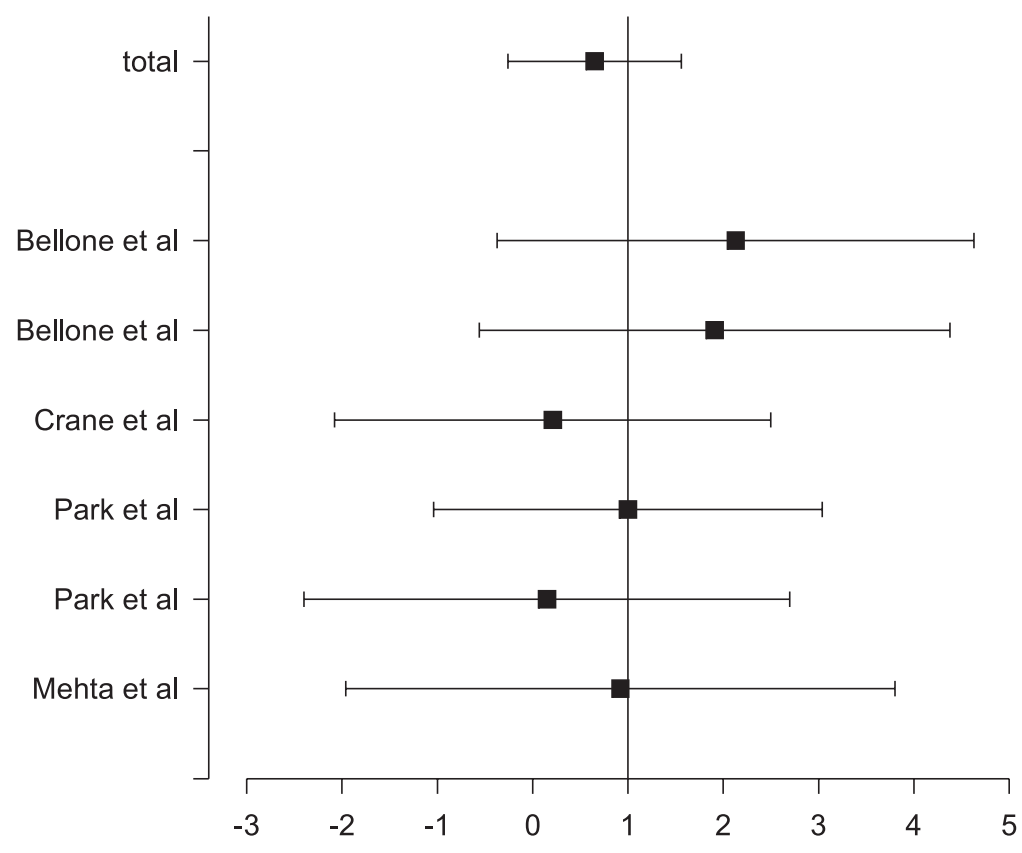

CPAP = continuous positive airway pressure

BIPAP = bilevel continuous positive airway pressure

Figure 1 - ODDS ratio of endotracheal intubation requirement in the studies comparing CPAP and bilevel-PAP

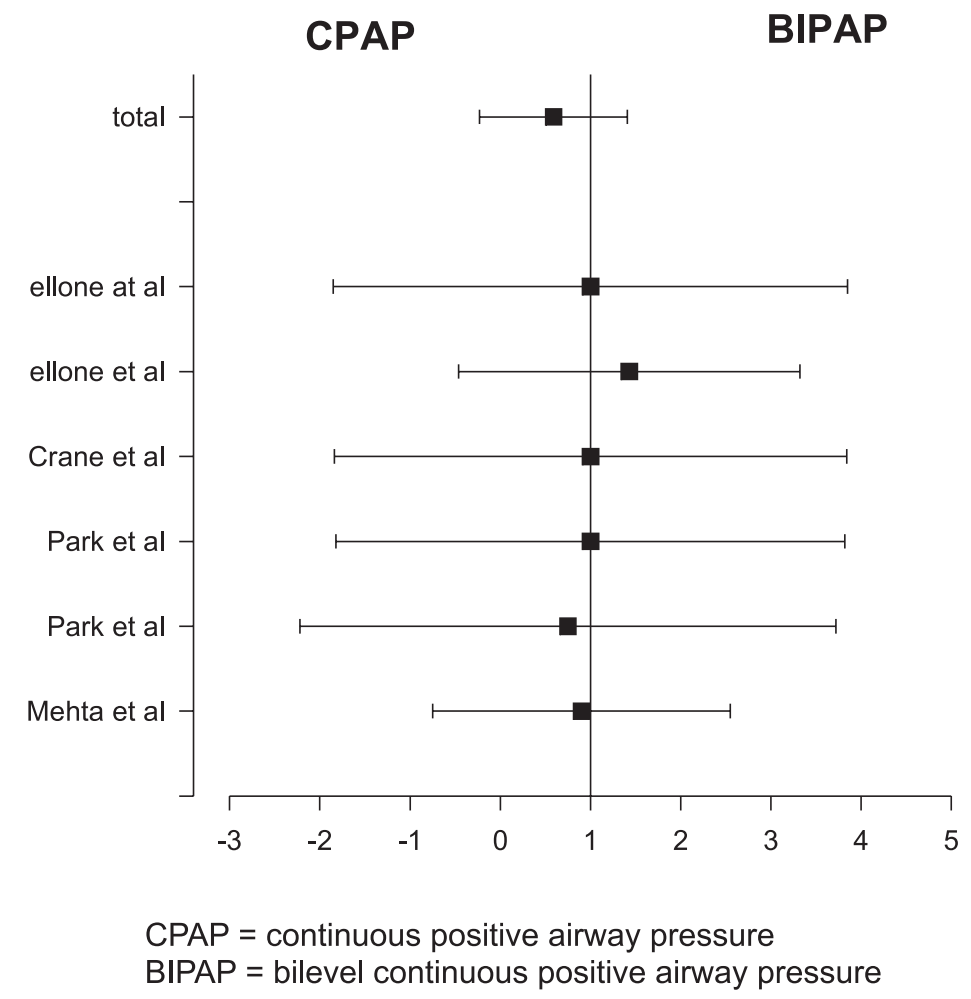

Figure 2 - ODDS ratio of acute myocardial infarction in the studies comparing CPAP and bilevel-PAP 
els of pressure may not be useful, ${ }^{8}$ but higher expiratory pressure levels can reduce the requirement for endotracheal intubation. $^{5}$

\section{CONCLUSION}

In conclusion, the analysis of the current literature shows that noninvasive ventilation applied by CPAP or
bilevel-PAP is safe, and the two approaches have similar effects and are effective in preventing the need for endotracheal intubation in patients with respiratory distress of cardiac origin. The results support the concept that positive intrathoracic positive pressure must be seen as a nonpharmacological form of treatment of acute pulmonary edema, rather than only as a supportive measure.

\section{RESUMO}

Park M, Lorenzi-Filho G. Uso da ventilação não invasiva no tratamento de pacientes com edema agudo de pulmão cardiogênico. Clinics. 2006;61(3):247-52.

Pesquisamos a literatura atual usando a base de dados MEDLINE para encontrar evidências consistentes sobre o uso da ventilação não invasiva em pacientes com edema agudo de pulmão cardiogênico. Foram encontrados 18 estudos demonstrando que a ventilação não invasiva aplicada por CPAP ou bilevel-PAP é segura, tem efeitos similares e é efetiva em reduzir a necessidade de intubação traqueal em pacientes com desconforto respiratório de origem cardíaca. Os resultados reforçam o conceito que a pressão positiva intratorácica deve ser considerada um forma não farmacológica de tratamento do edema agudo de pulmão cardiogênico e não simplesmente uma medida de suporte.

UNITERMOS: Edema pulmonar. Insuficiência respiratória. Respiração artificial. Ventilação mecânica. Terapia respiratória.

\section{REFERENCES}

1. Bersten AD, Holt AW, Vedig AE, Skowronski GA, Baggoley CJ. Treatment of severe cardiogenic pulmonary edema with continuous positive airway pressure delivered by face mask. N Engl J Med. 1991;325:1825-30

2. Lin M, Yang YF, Chiang HT, Chang MS, Chiang BN, Cheitlin MD. Reappraisal of continuous positive airway pressure therapy in acute cardiogenic pulmonary edema. Short-term results and long-term followup. Chest. 1995; 107:1379-86.

3. Mehta S, Jay GD, Woolard RH, Hipona RA, Connolly EM, Cimini DM, et al. Randomized, prospective trial of bilevel versus continuous positive airway pressure in acute pulmonary edema. Crit Care Med. 1997;25: 620-8.

4. Masip J, Betbese AJ, Paez J, Vecilla F, Canizares R, Padro J, et al. Noninvasive pressure support ventilation versus conventional oxygen therapy in acute cardiogenic pulmonary oedema: a randomised trial. Lancet. 2000;356:2126-32.

5. Park M, Sangean MC, Volpe MS, Feltrim MI, Nozawa E, Leite PF, et al Randomized, prospective trial of oxygen, continuous positive airway pressure, and bilevel positive airway pressure by face mask in acute cardiogenic pulmonary edema. Crit Care Med. 2004;32:2407-15.

6. Park M, Lorenzi-Filho G, Feltrim MI, Viecili PR, Sangean MC, Volpe $\mathrm{M}$, et al. Oxygen therapy, continuous positive airway pressure, or noninvasive bilevel positive pressure ventilation in the treatment of acute cardiogenic pulmonary edema. Arq Bras Cardiol. 2001;76:221-30.
7. Crane SD, Elliott MW, Gilligan P, Richards K, Gray AJ. Randomised controlled comparison of continuous positive airways pressure, bilevel non-invasive ventilation, and standard treatment in emergency department patients with acute cardiogenic pulmonary oedema. Emerg Med J. 2004;21:155-61.

8. Nava S, Carbone G, DiBattista N, Bellone A, Baiardi P, Cosentini R, et al. Noninvasive ventilation in cardiogenic pulmonary edema: a multicenter randomized trial. Am J Respir Crit Care Med. 2003;168:1432-7

9. L'Her E, Duquesne F, Girou E, de Rosiere XD, Le Conte P, Renault S, et al. Noninvasive continuous positive airway pressure in elderly cardiogenic pulmonary edema patients. Intensive Care Med. 2004:30:882-8

10. Chadda K, Annane D, Hart N, Gajdos P, Raphael JC, Lofaso F. Cardiac and respiratory effects of continuous positive airway pressure and noninvasive ventilation in acute cardiac pulmonary edema. Crit Care Med. 2002;30:2457-61.

11. Bellone A, Barbieri A, Ricci C, Iori E, Donateo M, Massobrio M, et al. Acute effects of non-invasive ventilatory support on functional mitral regurgitation in patients with exacerbation of congestive heart failure. Intensive Care Med. 2002;28:1348-50.

12. Bellone A, Vettorello M. The role of continuous positive airway pressure in diastolic heart dysfunction. Intensive Care Med. 2005. 
13. van den Berg PC, Jansen JR, Pinsky MR. Effect of positive pressure on venous return in volume-loaded cardiac surgical patients. J Appl Physiol. 2002;92:1223-31.

14. Mehta S, Liu PP, Fitzgerald FS, Allidina YK, Douglas BT. Effects of continuous positive airway pressure on cardiac volumes in patients with ischemic and dilated cardiomyopathy. Am J Respir Crit Care Med. 2000;161:128-34.

15. Philip-Joet FF, Paganelli FF, Dutau HL, Saadjian AY. Hemodynamic effects of bilevel nasal positive airway pressure ventilation in patients with heart failure. Respiration. 1999;66:136-43.

16. Bellone A, Monari A, Cortellaro F, Vettorello M, Arlati S, Coen D. Myocardial infarction rate in acute pulmonary edema: noninvasive pressure support ventilation versus continuous positive airway pressure. Crit Care Med. 2004;32:1860-5.
17. Sharon A, Shpirer I, Kaluski E, Moshkovitz Y, Milovanov O, Polak R, et al. High-dose intravenous isosorbide-dinitrate is safer and better than Bi-PAP ventilation combined with conventional treatment for severe pulmonary edema. J Am Coll Cardiol. 2000;36:832-7.

18. Cross AM, Cameron P, Kierce M, Ragg M, Kelly AM. Non-invasive ventilation in acute respiratory failure: a randomised comparison of continuous positive airway pressure and bi-level positive airway pressure. Emerg Med J. 2003;20:531-4.

19. Bellone A, Vettorello M, Monari A, Cortellaro F, Coen D. Noninvasive pressure support ventilation vs. continuous positive airway pressure in acute hypercapnic pulmonary edema. Intensive Care Med. 2005;31:80711.

20. Wysocki M. Noninvasive ventilation in acute cardiogenic pulmonary edema: better than continuous positive airway pressure? Intensive Care Med. 1999;25:1-2. 